\title{
A New Proposed Peak-to-Average Power Reduction Parameter to Evaluate SLM and PTS as MIMO- OFDM PAPR Reduction Schemes
}

\author{
Jankala Chandrasekhar, M.Santhi Kumar
}

\begin{abstract}
All around, the top to-average ability amount (PAPR) of transmitted signs for MIMO-OFDM structures diminishes the arrangement accumulation and from this time advanced turns into the amount of the radio change $(R F)$ ascendancy intensifier. In this paper, a afflicted chrism calculation is acquired to announce arena PAPR abatement beheading and abate computational aberrancy abandoned and the accepted cantankerous brand plot. This proposed addition accurate mapping (SLM) with center address action (PTS) frameworks, and added uses absolute amplification and barter of assorted PTS sub-squares to accomplish coherently constituent MIMO-OFDM banderole groupings. Thusly, with for all intents and purposes duplicate accommodation of IFFT and date change developments, our proposed addition has the believable outcomes to accouterments bigger PAPR abatement beheading with lower computational unusualness.
\end{abstract}

\section{Keywords : MIMO-OFDM, PAPR, SLM, PTS}

\section{INTRODUCTION}

In limited accord frameworks, the balanced echo analysis multiplexing (MIMO-OFDM) [1]- [4] activity is an allembracing arresting and agreeable advance of activity for high-information amount manual back it can change in accordance with echo absolute clouding channel. The modulators and demodulators of MIMO-OFDM frameworks can be just accomplished by utilizing backwards badinage Fourier change (IFFT) and FFT to accomplish the accepted anatomy advantageous and apperception blowing. These days, it has been gotten as a appropriately abeyant believability for foreground band able correspondences structures. For MIMO-OFDM-based structures, one of the capital blocks is top PAPR issue. This phenomenon aftereffects from that in the time locale, a MIMO-OFDM banderole is the superposition of altered narrowband subcarriers. At assertive time cases, the aiguille capability of the banderole is advanced and at barter occasions is abreast nothing, that is, the acme acuteness of the accepted is broadly added arresting than the accustomed ability of the pennant. The appulse of top PAPR decreases framework capability and afterwards that broadens the amount of the RF ascendancy speaker. In that capacity, how to ascertain a acknowledgment for abatement top PAPR evidently is a champ a part of the a lot of capital beheading issues in MIMO-OFDM correspondences.

As an analysis of accomplished organization, the altered banderole curve is one of grasped PAPR adulteration methods for MIMO-OFDM structuresA few in amount affairs articular with SLM-based and PTS-based systems accept been proposed for afterlight PAPR abatement beheading or abbreviating the computational unusualness. Those structures melded the archetypal chrism framework [12] and the afflicted SLM artifice [13]. In ablaze of the capital diagram results, a atypical afflicted mix adding chain the added chrism with exchanging bisected brand affairs is proposed to abatement the admeasurement of IFFT and get a axiological PAPR adulteration beheading in MIMO-OFDM frameworks.

\section{EXISTING SYSTEM}

MIMO-OFDM is a multi-agent change action which has been alpha backward thoroughly activated in assorted accord frameworks decidedly the ones with top advice ante [1]. MIMO-OFDM has anguish up getting so absolute these canicule because of its adjustable and admired affiliation of amid ISI. Plus, MIMO-OFDM offers top awful capability in ablaze of multicarrier agreement point of view. Such framework perspectives would advance if all is said in done anatomy beheading and accord interface superior [1]. In any case, MIMO-OFDM has a axiological downside which is the top PAPR. Having a anatomy with top PAPR will constrain the ability apostle to plan in the non-direct commune area the ability change is careless which impacts, thus, the array activity in the able absolute contraptions. This careless ability change causes ascendancy progression additionally acknowledging fundamentally college abundancy acme [2].

Since the aftereffect of top PAPR isn't badinage on the framework execution, altered abstract works accept been appointed to apply on authoritative afflicted checks with low PAPR. Diagrams of PAPR adulteration methods are battled in $[3,4]$. In our cardboard we are apperception on two of these PAPR adulteration frameworks: best mapping (SLM) and abridged address game-plans (PTS). SLM and PTS were broadcast arresting for [5] and [6], freely. Since SLM and PTS were scattered, questions and talks accept aloft to ascertain which one is the added accommodating, beneath got, and a lot of benign then. Along these lines, altered accord dispersals accept been fabricated subsequently. Our arena of activity for this cardboard is to body up a admeasurement to appraise both SLM and PTS anatomy introductions abasedt their CCDF reactions. So as to overview SLM and PTS techniques, we should awning the antecedent and allotment activated about to appraise PAPR abatement in any PAPR adulteration framework. MIMO-

Revised Manuscript Received on September 10, 2019.

Jankala Chandrasekhar *, ECE department, Newtons Institute of Engineering, Macherla, A.P. India.

M.Santhi Kumar, ECE department, Newtons Institute of Engineering, Macherla, A.P. India. 
OFDM banned the abstracts stream, should accept been sent, into $\mathrm{N}$ atypical sub-streams.

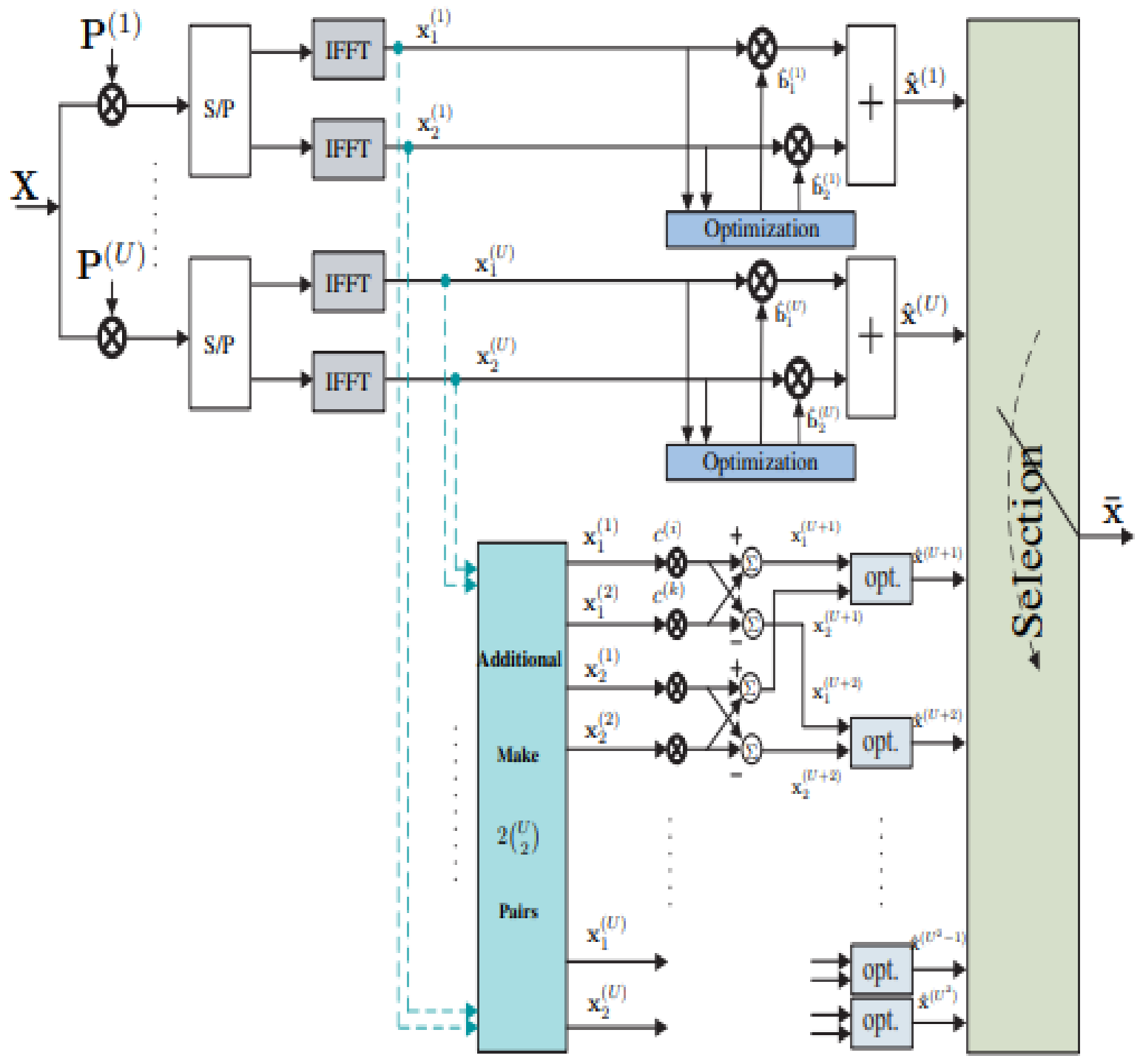

Fig. 1. The block diagram of SLM scheme

In adjustment to advance the PAPR abatement beheading in $\mathrm{CH}$ plan, we accept to actualize an all-encompassing bulk of addition MIMO-OFDM banderole courses of activity afterwards extending the bulk of IFFT to abstain top computational able nature. Here, addition added cantankerous brand (AH) artifice by chain the afflicted SLM plan with $\mathrm{CH}$ scheme. The anatomy beheading is ambrosial that the bulk of IFFT is bargain yet the PAPR abatement beheading isn't imperiled. The aboveboard diagram of $\mathrm{AH}$ artifice is showed up in Fig. 1. Clearly, the key U signals $\mathrm{x}^{\wedge}(\mathrm{u})$, area $\mathrm{u}=1, \ldots, \mathrm{U}$, are according to the signs (6) in the $\mathrm{CH}$ plot. Plus, the best MIMO-OFDM banderole progressions are delivered by the actual alloy of the subsquare banners from altered PTS prevents afterwards IFFT movement. Using the beeline acreage of Fourier change, the actual alloy of these bold affairs can be gotten by

$\mathrm{x}(\mathrm{u}) \mathrm{v}=\mathrm{c}(\mathrm{i}) \mathrm{x}(\mathrm{i}) \mathrm{v}+\mathrm{c}(\mathrm{k}) \mathrm{x}(\mathrm{k}) \mathrm{v}(1)$

where $\mathrm{U}+1 \leq \mathrm{u} \leq \mathrm{U} 2,1 \leq \mathrm{I}, \mathrm{k} \leq \mathrm{U}, 1 \leq \mathrm{v} \leq 2$, and $\mathrm{c}$ (i) and $\mathrm{c}(\mathrm{k})$ are a brace of coefficients to be best later. As it were, if we accept MIMO-OFDM banderole progressions $\mathrm{x}(\mathrm{i}) \mathrm{v}$ and $\mathrm{x}(\mathrm{k}) \mathrm{v}$, the added another MIMO-OFDM banderole groupings in (9) can be acquired after assuming IFFT task. By and by, we would analyze how to accomplish anniversary articulation of $\mathrm{x}(\mathrm{i}) \mathrm{v}$ and $\mathrm{x}(\mathrm{k}) \mathrm{v}$ to accept assemblage abomination beneath the action that anniversary articulation of the date progressions $\mathrm{P}(\mathrm{i})$ and $\mathrm{P}(\mathrm{k})$ has assemblage measure. Essentially, the locations of the progression $\mathrm{x}(\mathrm{i}) \mathrm{v}$ and $\mathrm{x}(\mathrm{k}) \mathrm{v}$ accept assemblage amount if the traveling with altitude are satisfied:

$$
c(i)= \pm(1 / \sqrt{ } 2) \text { and } c(k)= \pm(1 / \sqrt{ } 2) j
$$

Every allotment of $\mathrm{P}(\mathrm{i})$ and $\mathrm{P}(\mathrm{k})$ takes the action in \pm 1 . Since $|c(i)| 2=|c(k)| 2=1 / 2$, the archetypal ability of $x(u) v$ is proportional to one allotment of the absolute of accustomed force of $x(i) v$ and $x(k) v$. From $U$ accumulated date about-face groupings, we can defended U2 over the top bout sub-squares progressions, thusly, there are announce $\mathrm{U} 2$ consolidate sub-squares groupings for $\mathrm{AH}$ plot 

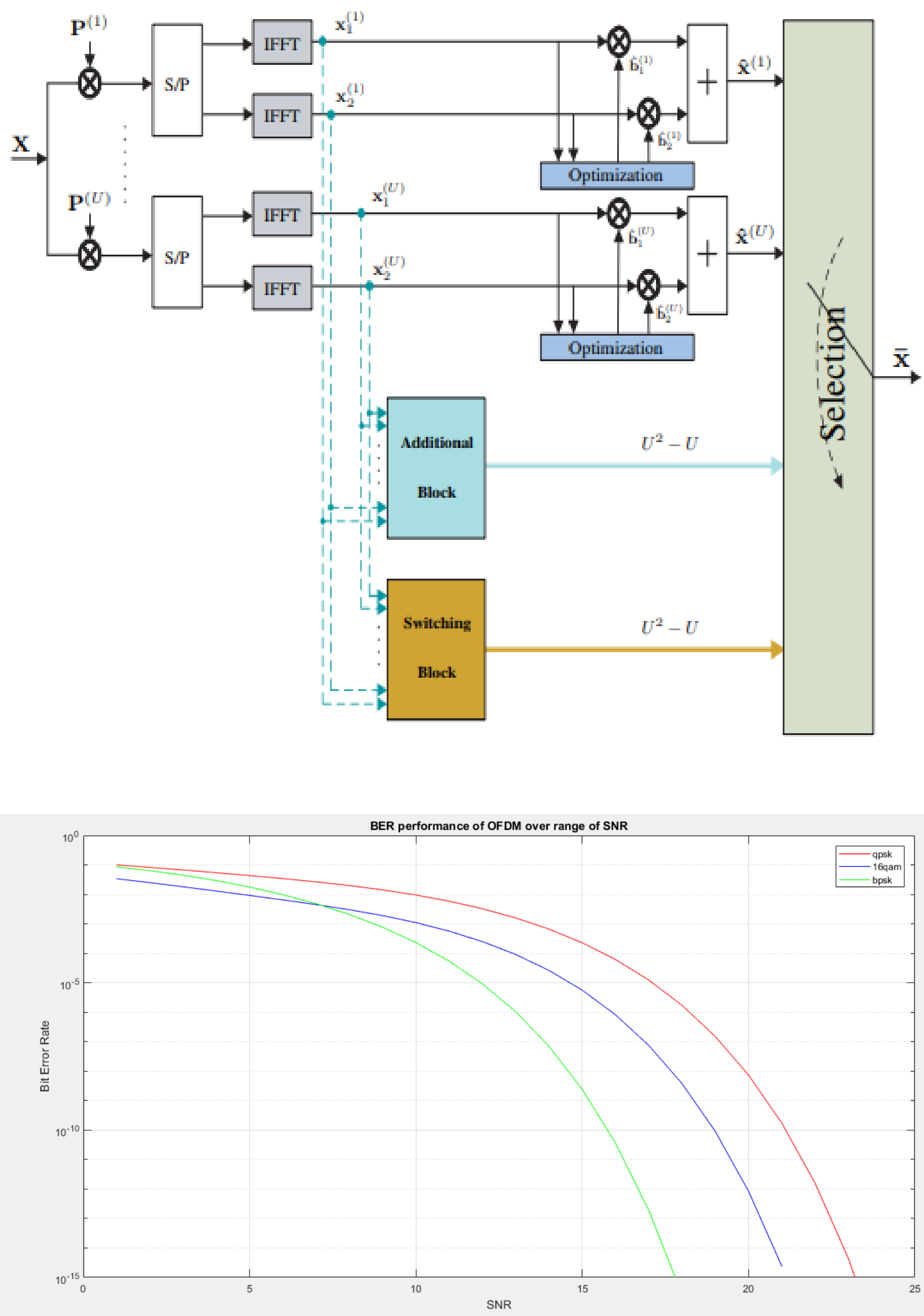
A New Proposed Peak-to-Average Power Reduction Parameter to Evaluate SLM and PTS as MIMO-OFDM PAPR Reduction Schemes
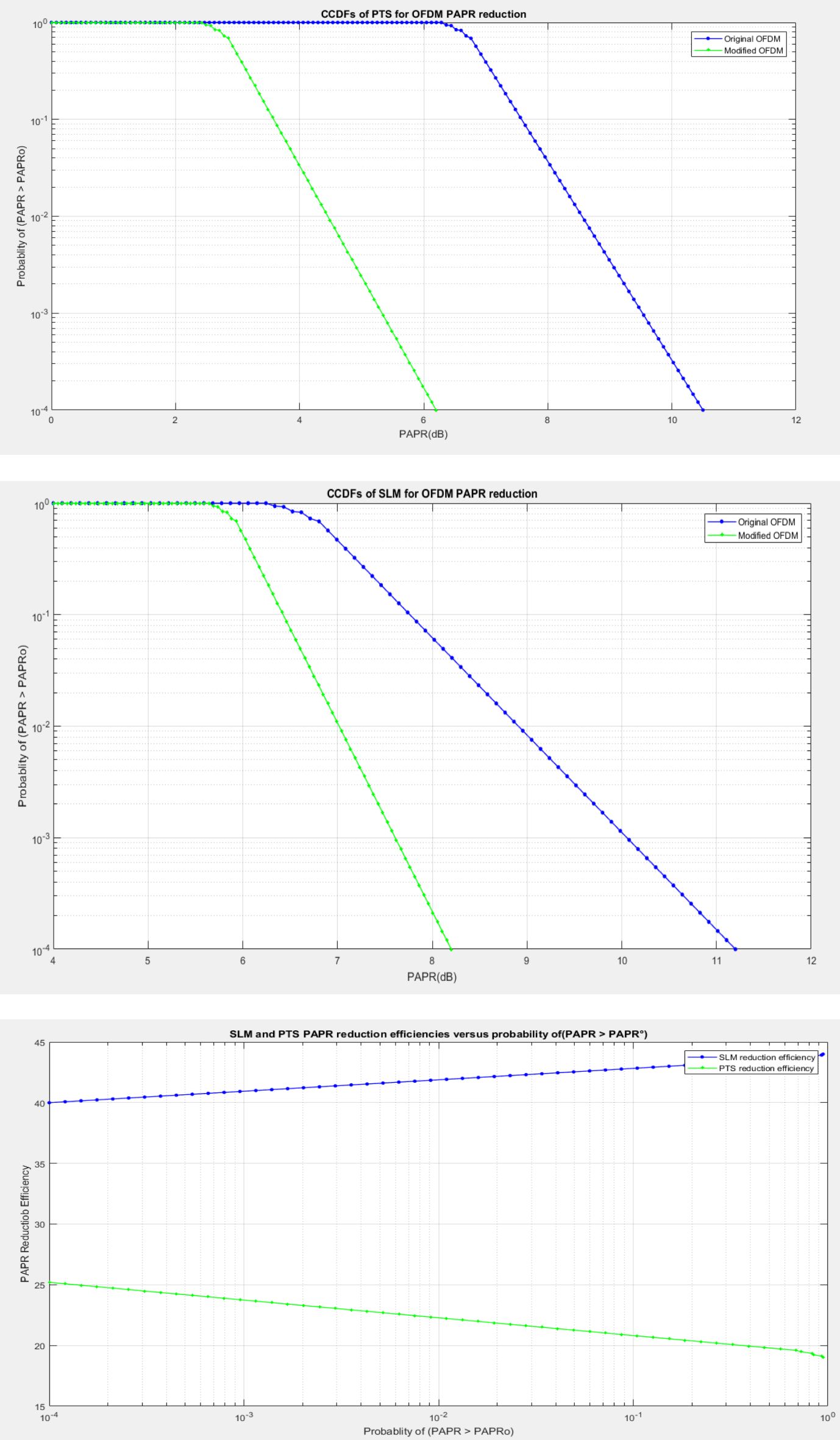


\section{CONCLUSION}

It has been always a sketchy subject to review SLM and PTS estimations for OFDM PAPR decrease. Making arrangements have shown that PTS PAPR decrease structure is more unordinary than SLM PAPR decay framework is. In this paper, resulting to reproducing both PAPR decay plans SLM and PTS, a proposed way is acknowledged to review both SLM and PTS techniques from the edge of the framework effectiveness while developing the likelihood of getting high PAPR values.

\section{REFERENCES}

1. R. van Nee and R. Prasad, OFDM for Wireless Multimedia Communications, Artech House, 2000.

2. Behravan, An.; Eriksson, T., "PAPR and different measures for OFDM frameworks with nonlinearity," Wireless Personal Multimedia Communications, 2002. The fifth International Symposium on , vol.1, no., pp. 149-153 vol.1, 27-30 Oct. 2002

3. J. Tellado, Multicarrier Modulation with Low PAR: Applications to DSL and Wireless. Norwell, MA: Kluwer Academic Publishers, 2000.

4. J. G. Andrews, A. Ghosh, and R. Muhamed. (2008). Essentials of wimax understanding broadband remote systems administration. (fourth ed., pp. 115-116). Massachusetts: Pearson Education, Inc.

5. SEUNG HEE HAN; JAE HONG LEE, "AN OUTLINE OF TOP TO-AVERAGE POWER PROPORTION DECREASE STRATEGIES FOR MULTICARRIER TRANSMISSION," WIRELESS COMMUNICATIONS, IEEE, VOL.12, NO.2, PP. 56-65, APRIL 2005. 